\title{
Yellow Plugs: An Additional Dermoscopic Criterion in the Diagnosis of Primary Cutaneous B-Cell Lymphoma
}

\author{
Claudio Conforti ${ }^{1}$, Roberta Giuffrida ${ }^{2}$, Arianna Dri ${ }^{1}$, Iris Zalaudek ${ }^{1}$, Nicola Di Meo ${ }^{1}$
}

1 Dermatology Clinic, Maggiore Hospital, University of Trieste, Trieste, Italy

2 Department of Clinical and Experimental Medicine, Dermatology, University of Messina, Italy

Key words: cutaneous lymphoma, dermoscopy, lymphomas, diagnosis

Citation: Conforti C, Giuffrida R, Dri A, Zalaudek I, Di Meo N. Yellow plugs: an additional dermoscopic criterion in the diagnosis of primary cutaneous b-cell lymphoma. Dermatol Pract Concept. 2022;12(1):e2022006. DOI: https://doi.org/10.5826/dpc.1201a06

Accepted: April 25, 2021; Published: January 2022

Copyright: @2022 Conforti et al. This is an open-access article distributed under the terms of the Creative Commons

Attribution-NonCommercial License (BY-NC-4.0), https://creativecommons.org/licenses/by-nc/4.0/, which permits unrestricted noncommercial use, distribution, and reproduction in any medium, provided the original authors and source are credited.

Funding: None.

Competing interests: None.

Authorship: All authors have contributed significantly to this publication

Corresponding author: Roberta Giuffrida, MD, Department of Clinical and Experimental Medicine, Dermatology, University of Messina, Messina, Italy. Email: roberta_giuffrida@hotmail.it

\section{Introduction}

Primary cutaneous B-cell lymphoma (PCBCL) is a lymphoproliferative $\mathrm{B}$-cell disorder involving only the skin at the time of diagnosis. PCBCLs comprise a group of rare disease that account for $20 \%-25 \%$ of all cutaneous lymphomas, and they are classified into 3 main types: (i) follicle center lymphoma (the most common and usually indolent), (ii) marginal zone lymphoma, and (iii) diffuse large B-cell lymphoma (the most aggressive) [1].

\section{Case Presentation}

We present the case of a 63-year-old otherwise healthy Caucasian woman who sought consultation at our skin cancer department for a cluster of lesions localized on the right cheek, presenting as pinkish-erythematous, slow-growing, firm nodules, irregularly oval in shape, with well-defined borders, that had been enlarging over the past 8 years. The largest nodule was $30 \mathrm{~mm}$ in diameter (Figure 1A). The patient denied correlation with traumas or arthropods bites and felt no local pain or itch. No other cutaneous lesions were found at total-body checkup. Systemic involvement was ruled out with laboratory tests, ultrasound examination of lymph node stations, and computed axial tomography of chest and abdomen.

Dermoscopic evaluation ( $\times 20$; DermLite, 3Gen) showed the presence of an erythematous background with salmon-colored areas, arborizing vessels, and peculiar yellow plugs surrounded by well-defined white circles (Figure 1B). The integration of the clinical history and information provided by dermoscopy led to the hypothesis of B-cell lymphoma. A 5-mm punch biopsy was performed, and the histopathological report confirmed the clinical diagnosis of cutaneous B-cell lymphoma, follicle center subtype. 


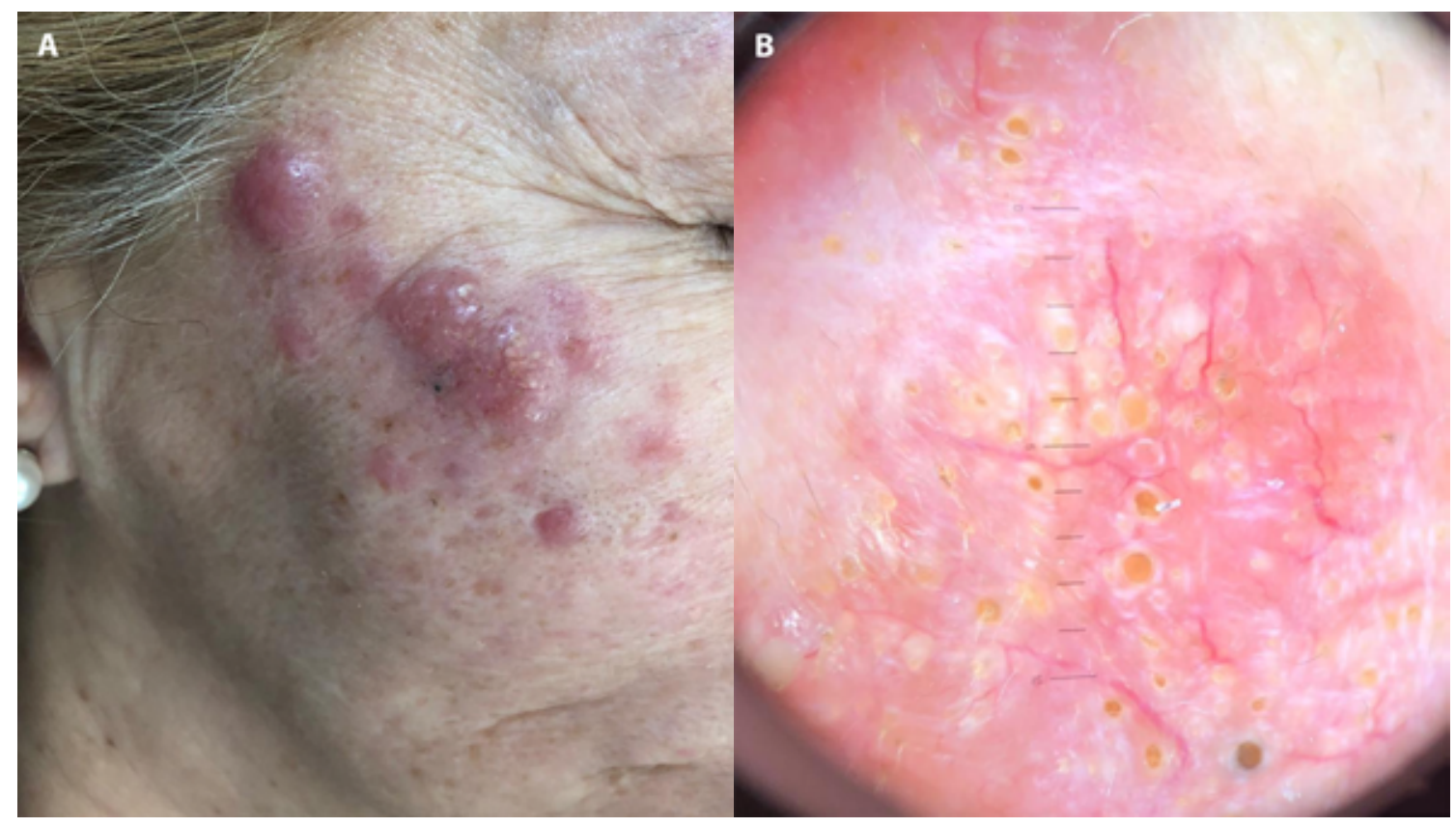

Figure 1. (A) Clinical image of the follicle center of PCBCL: pinkish-erythematous firm nodules, irregularly oval in shape, with well-defined borders, located on the cheek. (B) Dermoscopy of the follicle center of PCBCL: erythematous background, salmon-colored areas, arborizing vessels, and yellow plugs surrounded by well-defined white circles.
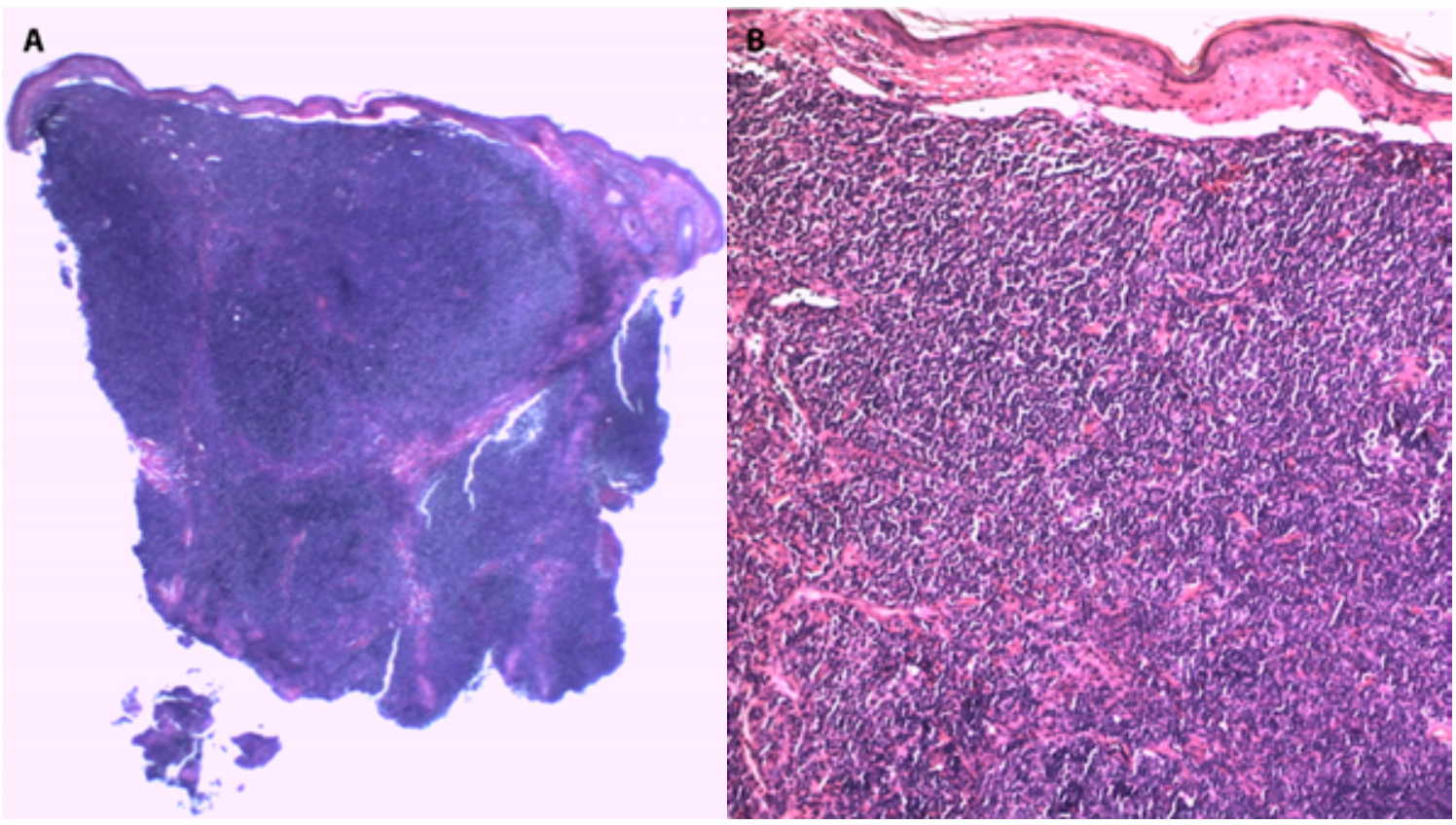

Figure 2. (A) Tissue fragment of PCBCL obtained by punch biopsy (standard H\&E, magnification $\times 10)$. (B) Histopathological picture of the lymphoma: nodular lymphoid infiltrates arranged in a follicular pattern in the dermis (standard H\&E, magnification $\times 20$ ).

\section{Conclusions}

Overall, PCBCLs may clinically appear as papules, plaques, or nodules of different shapes, number, colors, and body locations. Differential diagnosis includes a wide spectrum of pathologies, such as basal cell carcinoma, amelanotic melanoma, arthropod bite scar, or keloid, and for this reason a skin biopsy is always needed to arrive at the correct diagnosis, even if dermoscopy can help rule out other skin disorders [2].

Currently available literature states that white circles and salmon-colored areas are the main common dermoscopic features of PCBCLs. Regarding vascularization, arborizing or serpentine vessels could be found, sometimes simultaneously, resulting in a polymorphous vascular pattern. Scales are a further criterion highlighted in a retrospective study [3-5]. 
The presence of yellow plugs dermoscopic examination of PCBCLs have yet to be reported.

In our patient, yellow plugs were detectable throughout the entire lesion, and particularly evident in the central area. The term "yellow plugs" refers to yellow structures surrounded by white circles combined with an erythematous background with salmon-colored areas and arborizing vessels. The histopathological examination described nodular lymphoid infiltrates arranged in a follicular pattern in the dermis. The follicles were atypical because of the absence of polarization and mantle and showed a reduction in the number of macrophages (Figure 2, A and B). The cell immunophenotypic patterns were CD20+, Bcl-6+, CD10+ and partial $\mathrm{Bcl}-2+$. There was no evidence of adnexal involvement, so it can be assumed that the accentuated follicular plugging was the result of the upward displacement of the epidermis by the underlying conspicuous dermal infiltrate.

Although dermoscopy cannot replace the histopathological examination, the combination of an erythematous background, salmon-colored areas, white circles, arborizing vessels and/or scales, as previously reported by other authors, as well as peculiar yellow plugs, may be helpful in considering PCBCLs in the differential diagnosis of cutaneous pink nodules. The peculiar features listed can help in promptly suspecting a possible lymphoma and in identifying the correct site for biopsy. Moreover, dermoscopy can be used to monitor recurrences. Since PCBCLs comprise a group of rare diseases, further investigations are needed to deepen the knowledge on the subject.

Informed consent: Written informed consent for publication of her clinical details and clinical images was obtained from the patient.

\section{References}

1. Willemze R, Cerroni L, Kempf W, et al. The 2018 update of the WHO-EORTC classification for primary cutaneous lymphomas. Blood. 2019;133(16):1703-1714. DOI: 10.1182/ blood-2018-11-881268. PMID: 30635287. PMCID: PMC6473500.

2. Conforti C, Giuffrida R, Vezzoni R, Resende FSS, di Meo N, Zalaudek I. Dermoscopy and the experienced clinicians. Int J Dermatol. 2019 Jun 20. DOI: 10.1111/ijd.14512. PMID: 31222814.

3. Mascolo M, Piccolo V, Argenziano G, et al. Dermoscopy pattern, histopathology and immunophenotype of primary cutaneous b-cell lymphoma presenting as a solitary skin nodule. Dermatology. 2016;232(2):203-207. DOI: 10.1159/000442251. PMID: 26694025.

4. Geller S, Marghoob AA, Scope A, Braun RP, Myskowski PL. Dermoscopy and the diagnosis of primary cutaneous B-cell lymphoma. J Eur Acad Dermatol Venereol. 2018;32(1):53-56. DOI: 10.1111/jdv.14549. PMID: 28846171; PMCID: PMC5773353.

5. Bombonato C, Pampena R, Lallas A, Giovanni P, Longo C. Dermoscopy of lymphomas and pseudolymphomas. Dermatol Clin. 2018;36(4):377-388. DOI: 10.1016/j.det.2018.05.005. PMID: 30201147. 